\title{
Design infrastructures: proposing alternative strategies for countries with a lower maturation of design culture
}

\author{
Nina Costa ${ }^{1,2}$, Vasco Branco ${ }^{1,2}$, Rui Costa ${ }^{1,2}$, Afonso Borges ${ }^{1,2}$, \\ Raul Cunca ${ }^{1,3}$, António Modesto ${ }^{1,4}$, Ana Vieira Silva ${ }^{1,5}$ \\ ${ }^{1}$ Research Institute for Design, Media and Culture (ID+), Portugal \\ ${ }^{2}$ University of Aveiro, Aveiro, Portugal \\ ${ }^{3}$ Faculty of Fine Arts, Lisbon University, Lisbon, Portugal \\ ${ }^{4}$ Faculty of Fine Arts, Porto University, Porto, Portugal \\ ${ }^{5}$ Polytechnique Institute of Cávado e do Ave, Barcelos, Portugal
}

\begin{abstract}
In Europe, Design Centers and Associations are considered as key infrastructures to efficiently promote and represent the discipline. However, in some countries with a lower maturation of Design culture - such as the case of Portugal - there are no official actors fully dedicated to these activities. Previous research indicated Design schools as a potential alternative infrastructure to promote and represent Design, but further research is needed to understand what they can learn/adapt from the activities currently undertaken by Centers and Associations. This paper maps the European landscape looking in particular at BEDA (Bureaux of European Design Association) members. Based on these insights and recent infrastructuring literature, it develops adapted strategies for observation activities to test with Design schools in the Portuguese territory. The results obtained are a first step to bring countries with lower maturation of design culture under the EU Design Ecosystem radar.
\end{abstract}

Keywords: Design Observation · Design Networks · Infrastructuring · Design Schools

\section{Introduction}

Design is recognized as a key factor of innovation [1], as well as a cultural mediator and decisive agent in increasing the quality of life. To better capture its multiple realities and develop more adequate national design policies, several models and indicators have emerged [2]. According to Terence Love [3], [4], Design Centers such as the UK design council or the Danish Design Center, are considered as key infrastructures to guide and apply these models in Europe. Also characterized as gatekeepers, they adopt a central role in Design networks, providing access to, and connecting various elements in the Design ecosystem, giving them visibility [3], [4]. However, in some European countries, where there are no official entities dedicated to the representation and promotion of Design (e. g. Bulgari, Cyprus), information tends to be scattered and, as such, difficult to use. This can hamper the development of more performing Design systems in geographical areas where no central actor exists to perform this role. 
The Portuguese case falls into this latter category. After the closure of the Portuguese Design Center (2013) and the loss of representativeness of the national design associations, there have been few alternatives to represent and promote Design - and consequently for systematic data collection about the ecosystem. Moreover, the funding to undertake such operations is becoming thinner because of the socio-economic crisis installed. A previous study undertaken within the project "Towards a Design Observatory in Portugal" [5] proposed Design Schools network as a potential alternative design infrastructure to apply a distributed design observation approach. Built with a territorial reach and proximity to local communities, schools seem to be a fundamental national infrastructure which can contribute to the co-creation of more resilient Design observation systems. However, additional research is needed to confirm and explore this hypothesis.

Design infrastructures. Early notions of design infrastructures indicate Design Centers and associations as key components of wider design systems [3], [4]. Their presence or absence already acts as an indicator that differentiates between economies led by design; and economies whose knowledge and culture about the discipline is still developing. According to Love [3], [4] Design centers are made of complex connections, each with its own objectives, vision, mission and strategies and identifies four archetypes in particular: (i) Promotion: demonstrates how companies benefit from the use of design through case studies, products, storyboards, photographs and others; promotes government programs that support the use of design and activity improvement services; (ii) Consulting: usually offers skills and advice for product design, processes; patents, rights, design and development of new businesses; it can offer access to specific software for small and medium businesses; (iii) Services: has advanced resources and facilities to design, prototype, test various types of products and services; (iv) Investigation: focuses on research on multiple aspects of the discipline, provides access to data and research results on design. Studying these keystone structures is important to a better and more detailed understanding of the activities they develop, their main beneficiaries, operation mechanisms and resources allocated, as well as their role within design ecosystems. However, replicating such structures as-is might be ineffective given that - as mentioned by Love - having a mature design culture is a pillar for their continuance in the ecosystem. This condition has yet to be achieved in multiple countries across the globe.

More recent literature interprets infrastructuring as "continually renewing, complex socio-material relationships, in which embedded politics, voice and authorship are articulated components of the system" [6]; complex objects of design which need to account for emergent components of the ecosystem, plural views and need for intentional, long-term engagement/change [7]. Participatory infrastructuring refers to activities that focus on how we do and create capacity to do infrastructuring work, locally, with people and groups, with shared goals or interests, affected by and working in relation to the systems we seek to engage [7]. It is the work of creating resources that both socially and technically, enable adoption and appropriation beyond the initial design; and creates fertile ground to sustain a community of participants [6], [7], in an iterative loop of reflection-action [8]. Although this approach is increasingly relevant, 
there are still few empirical examples informing practitioners, researchers and other actors, on how to navigate within such complexity [8].

\section{Methodology}

Based on the challenges detailed in the previous chapter, this study's objectives are two folded: (1) to explore the current activities undertaken by key design infrastructures in Europe and understand the limitations and advantages of adopting/adapting their activities in geographical areas where there are no formal Design infrastructure; and (2) to develop adapted strategies for infrastructuring activities focused - in a first instance - on developing new design observation practices, like we are trying to do in Portugal. To achieve these objectives, we follow a two-stage research process. First, the paper characterizes the Centers and associations, members of BEDA (Bureau of European Design Associations). It collects the mission, activities and main beneficiaries of these Centers/Associations. It maps their emergence chronologically, and classifies their activities according to the archetypes proposed by Love [3] i.e. promotion, consulting, services and investigation. Based on the pillars of the Design Ecosystem Model proposed by Whicher [9] we also categorize the mains stakeholders/beneficiaries of these Centers. The model's main pillars are offer, demand, demand-offer - which we adapt, in this study, to designers, users and policy makers (government), respectively. Next, it looks more closely at the centers which have more prominent research/investigation activities. These steps rely on desktop research and qualitative data analysis [10], iteratively coding the available digital information about the Centers/associations 'websites. It also uses an interview with the current program director of the Danish Design Center to complement the research findings. Second, it reflects on the limitations and advantages of adapting and applying existing observation practices in countries such as Portugal, which does not have a formal representative Design infrastructure. Within the DesignOBS project, it debates and develops an infrastructuring work with the community in an attempt to infuse systematic design observation mechanisms.

\section{Results}

BEDA members characterization. BEDA has in total, 47 members from 25 different European countries. Bulgari, Czech Republic, Cyprus and Portugal - countries from the European Union - are not part of this list. The map (Fig 1) shows the year of foundation of these centers: half emerged before the 2000's, 20\% were created between 2000-2009, and $26 \%$ between 2010-2018. About half of the countries members of BEDA have more than one representative. France is the leading (and only) country, with 5 different centers/associations, followed by Germany with 4. England, Slovenia, Hungary, Netherlands, Spain and Belgium have 3 different centers/associations, members of BEDA. This data shows that the number of centers is not necessarily related with the demographic size or design companies operating in the country (e. g. UK and Slovenia 
have the same number of centers). Regarding the timeline in Fig 1, Hungary, Belgium, Estonia, and France created centers, sometimes, with less than one year apart. This data already indicates that certain centers/associations are representative of specific cities or regions as opposed to all the territory, providing a more detailed view of design integration within a certain geographical area.

Archetypes. In addition to this chronological analysis, and based on the information available on the website of each center/association, we applied the classification developed by Love $(2006,2007)$ i.e. promotion, counseling, services, investigation activities. Most European centers - with the exception of 10 cases - show polyvalent functions, fitting in multiple categories of activities (Fig 1), but mainly focused on Promotion and Counselling activities with $66 \%$ and $51 \%$ respectively; about one third provides Services; the eight members which have more evident Research activities constitute a much smaller part (17\%). Moreover, the only research center which fitted within all the categories is the Design Council (UK).

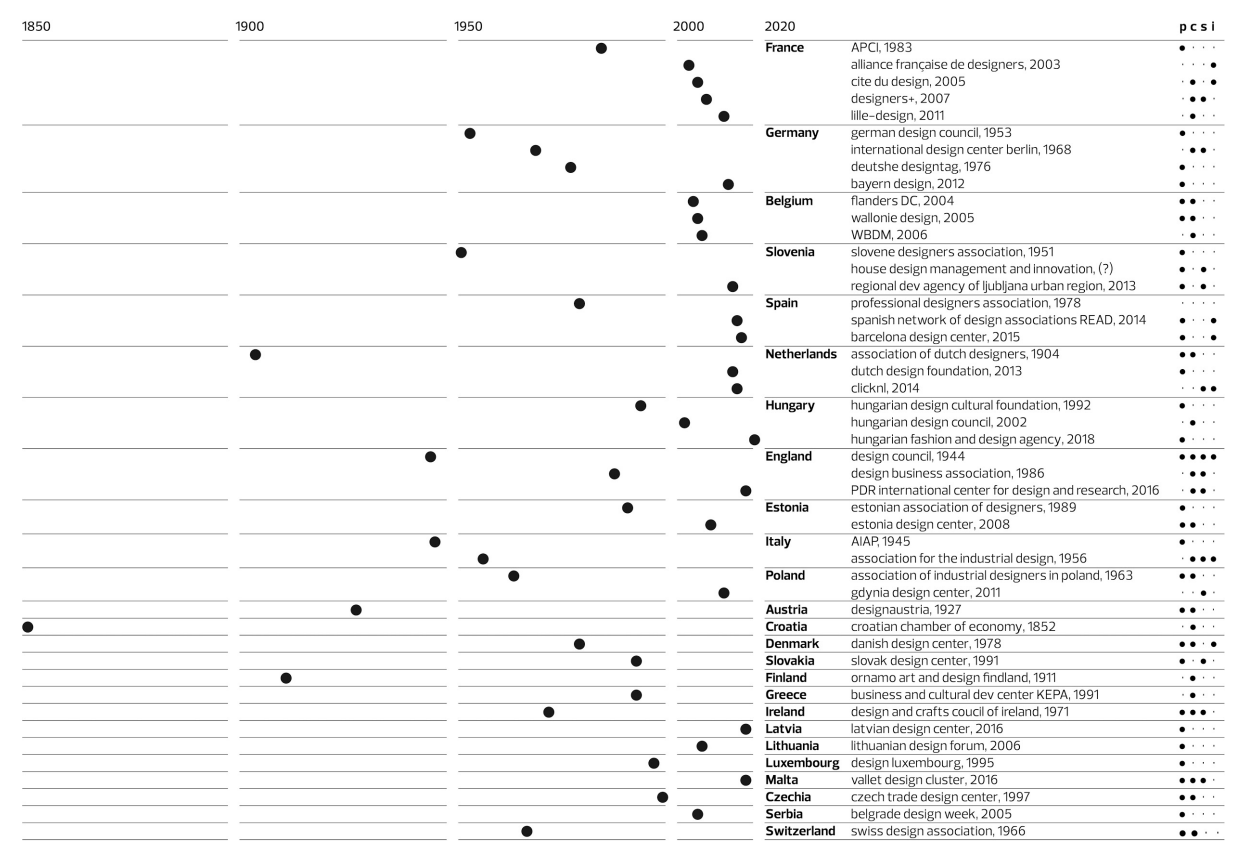

Fig 1. year of foundation and classification of BEDA members according to Love [3] promotion (p), counseling (c), services (s), investigation (i) (on the right).

Design Area. Evidence shows that most of the centers are focused on multiple areas of design, going from fashion, interior, industrial and graphic/communication design (74\%). A very small portion is focused on one specific design area only, whilst $10 \%$ are about Creative Industries as a whole (including communication science). Three members are not design-focused, but rather include design within business innovation and economic activity (Croatia, Greece and Slovenia). 
Stakeholders/beneficiaries. Evidence shows that an overwhelming part of members are focused on design professionals only (53\%). Centers which focus on both users and designers constitute $32 \%$ of the sample. Most websites focus on displaying best cases of products and services that demonstrate design craft and impact at socio-economic level, winning prizes and announcing contests (ex. DesignAustria). This gives visibility to design work at the national and international level. Associations such as ADI (Italy) regularly update a repository of design professionals in all or specific areas of design knowledge or present new regulations that affect/benefit design professionals (e. g. patents' rights, branding, intellectual property). Centers can also be more focused on users, connecting their needs with certain competencies and companies (ex. Dutch Designers Association). Few websites seem to be government oriented. Most of them do have a repository of professionals, but surprisingly, few present studies and/or encompassing information on the overall parts of the design ecosystem (e.g. education, research, designers, users, support, funding, policies), which could be used to develop public policy. We found some exceptions in Centers with research activities which we analyze below.

Centers with research activities. Results show that Centers/associations which undertake research activities develop state of the art design knowledge on topics mostly focused on industry and design profession, including (i) studies about intellectual property legal issues, (ii) case studies which demonstrate the impact of design infusion in multiple industry sectors (iii) state of the art knowledge about the design ecosystem, focused on adopting a critical approach to develop guidelines for improvement of the sector. Table 1 lists examples of topics of research of these centers.

Table 1. examples of research topics and projects of selected centers/associations.

\begin{tabular}{|l|l|}
\hline Center/ associations & Current research activities \\
\hline UK design council & $\begin{array}{l}\text { Series: black creatives, better places, design economy [11], } \\
\text { leading women in design, future of design }\end{array}$ \\
\hline DK danish design center & $\begin{array}{l}\text { Projects: design cities, future welfare, design startups, } \\
\text { danish design (DNA); cases: circular consumption, tech- } \\
\text { focused solutions, urban-mobility [12] }\end{array}$ \\
\hline $\begin{array}{l}\text { FR alliance française de } \\
\text { designers }\end{array}$ & $\begin{array}{l}\text { Studies: intellectual property, designers rights and } \\
\text { competencies, impact of covid in design profession }\end{array}$ \\
\hline FR cite du design & $\begin{array}{l}\text { Exploring the role of design within contemporary societies } \\
\text { and the relationship between arts/crafts and design }\end{array}$ \\
\hline NH clicknl & $\begin{array}{l}\text { Projects: video games, social cohesion, home for the elerly, } \\
\text { event experience (...); topics: energy transition and } \\
\text { sustainability, agriculture, water and food, healthcare (...) }\end{array}$ \\
\hline $\begin{array}{l}\text { ES Spanish network of design } \\
\text { associations (READ) }\end{array}$ & $\begin{array}{l}\text { Projects: deontological code, design strategy, Spanish } \\
\text { design ecosystem [13], design and public administration }\end{array}$ \\
\hline
\end{tabular}

The UK design council is one of the leading centers. Its website comprises four main parts: (1) presentation and mission of the Center, (2) strategic plan and offers (what we 
do), (3) calls for action and points of interaction with the general public (events, news, contacts), and (4) research results communicated via reports, interviews, stories, guidelines and recommendations. Although not as systematically, the DDC (DK) shares periodic studies showcasing the impact of design within the industrial sector. Recent projects have focused on understanding how design is accelerating businesses; and exploring the Danish design identity (DNA) in contemporary societies. Initiatives developed by READ (Spain) count with complementary research projects: one focused on creating a national strategy for design in Spain ("somos cultura, hacemos economia"), and another [13], more recent, aiming to collect and map the design resources and demand in the country.

\section{Infrastructuring: the Portuguese case}

Building on the insights of the previous section, we provide an analysis of the potential advantages and limitations of embedding existing practices within a territory with no supporting infrastructures. We use Portugal as a case and indicate alternative routes for infrastructuring currently being applied in the DesignOBS project.

Synergies and experiences. Creating partnerships or collaborations with international centers/associations can lever the project, providing guidelines, sharing experiences and giving some visibility to its initiatives. Following these guidelines, we explored new connections with other research international centers, including the DDC and the Cardiff Metropolitan University for its role in the development of the Design Ecosystem Model [14] which has been applied in diverse EU countries. DDC's collaboration and lessons learned emphasized the need to improve communication of design impact in multiple sectors, via case studies; using existing statistical data as well as social media information more efficiently; and lobbying the discipline at the government-level. Although structurally limited, these objectives were partially implemented or served as a guideline in our actions. A case study about design doctorates [15] demonstrated that the community needed to be more involved in data collection and curation - aspect which we embed in the development new designfocused databases through the involvement of REDE [16] - the National design school meeting, with 42 different professors/researchers, from 30 schools. The information that we currently have available is still not sufficient to have lobbying power at the government level but was so far sufficient to propose new practices regarding design research [17].

Instruments for inquiry. From the studies we had access to, existing mechanisms of data collection about design - either education, research, professionals, users etc. rely on statistical data collected by governmental-led entities (i.e. public databases); surveys addressing one part of the ecosystem; invitations for partnerships in design-related topics. Latest initiatives use workshops with multiple stakeholders (users, professionals, policy makers) to create an encompassing, simplified map of the design ecosystem - using it as a support to guide policy making for the discipline [14]. In 
Portugal, these processes are still being developed. In the first instance, our efforts are focused on collecting secondary data and building participatory instruments to enable the co-design of a first map of the ecosystem and making a compelling case about Design. The approach, model and instruments are evolving objects of design, cocreated with/by the community whose use depends on the feedback of multiple actors involved in the network.

Distributed and participatory network. One of the key differences between the Centers/Associations mentioned in Table 1 and Portugal, is the lack of a formal design infrastructure. To overcome this limitation, we adopted an alternative data collection approach partially based on a distributed network of actors/informants [15], [17] - the Design schools. Schools are currently the only infrastructure built with territorial reach and proximity to local actors and institutions; they do not heavily rely on governmental changes nor on intermittent funds that shifts every four years. Moreover, their involvement with the local systems can enrich design representation, create ownership of the data collected and bring forth issues which would go missing with a formal topdown approach. Knowledge transfer is a core mission of Schools, however, as entangled as it may be, the rules, roles, norms, advantages and tasks of informants within the observation-action loop are subject of continuous negotiation and inquiry via yearly meetings and an online digital and participatory platform. This aspect of infrastructuring and value creation for the actors involved in their multiple contexts and realities, is a key concern of the project as is the infusion of new practices of observation.

\section{Conclusions}

This study maps the design infrastructures currently available in Europe based on BEDA members, and explores how their best practices can be adopted/adapted in territories with lower maturation of design culture. The study's results show most centers are focused on promotion and counseling activities, with few oriented to design research/investigation, which are key to support the development of public policies. The question as to why this is so, given the increasing discussion about design and policy, should be further analyzed.

Additionally, research centers/associations do show a certain pattern of action, which we partially embed in the Portuguese case. Other structures, however, are harder to replicate. To overcome these issues, we propose distributed networks of observation and enabling participatory mechanisms of inquiry. This modus-operandi can be further replicated and expanded in countries with similar conditions.

Acknowledgments. This article is a result of the project Design Obs. Towards a design Observatory in Portugal: models, instruments, representation and strategies supported by Lisbon Regional Operational Program (LISBOA 2020) and the Competitiveness and Internationalization Operational Program (POCI-01-0145-FEDER-032445), under the 
PORTUGAL 2020 Partnership Agreement, through the European Regional Development Fund (ERDF) and FCT - Foundation for Science and Technology.

\section{References}

[1] NESTA, "The Innovation Index: Measuring the UK's Investment in Innovation and its Effects.," London, 2009.

[2] Whicher A., "Design ecosystems and innovation policy in Europe," Strateg. Des. Res. J., vol. 10, no. 2, pp. 117-125, 2017.

[3] Love T., "Design Centres as Elements of Design Infrastructure," SEE Des. Bull. Issue 2, vol. 44, no. 2, pp. 3-5, 2006.

[4] Love T., "Design Infrastructures : the Key To Design - Driven Socio - Economic," Int. Assoc. Scieties Des. Res., 2007.

[5] Branco V., Costa R., Costa N., Borges A., Cunca R., Modesto A., Silva A., "Towards a portuguese design observatory: models, instruments, representation and strategies (project description)," 2019. [Online]. Available: http://designobs.pt/. [Accessed: 07-Nov-2019].

[6] Agid S., “'Dismantle, change, build': Designing abolition at the intersections of local, large-scale, and imagined infrastructures,” Des. Stud., vol. 59, pp. 95-116, 2018.

[7] Vink J., Koskela-Huotari K., Tronvoll B., Edvardsson B., and Wetter-Edman K., "Service Ecosystem Design: Propositions, Process Model, and Future Research Agenda," J. Serv. Res., 2020.

[8] Bødker S., Dindler C., and Iversen O. S., "Tying Knots: Participatory Infrastructuring at Work," Comput. Support. Coop. Work, vol. 26, no. 1-2, pp. 245-273, 2017.

[9] Whicher A., G. Cawood, and A. Walters, "Research and Practice in Design and Innovation Policy in Europe," in Leading innovation through design. International Design management Research Conference, 2012, pp. 1-19.

[10] Miles M. B. and M. A. Huberman, Qualitative data analysis: an expanded sourcebook, Sage. 1994.

[11] Design Council, "The Design Economy 2018: The state of design in the UK," 2018.

[12] Danish Design Center, "Shaping the Next," 2019.

[13] Ecosistema del Diseno Espanhol, 2019. https://xn--ecosistemadeldiseo-30b.es/.

[14] Whicher A., Swiatek P., and Ward J., "Design4Innovation Policy Booklet 1: Mapping Design Ecosystems," 2018.

[15] Costa N., Branco V., Costa R., Borges A., Cunca R., Modesto A., Silva A., "Towards a Design Observatory: the Case of Scholarly Design Research in Portugal," Proc. Des. Soc. Des. Conf., vol. 1, pp. 827-836, 2020.

[16] Borges A., Silva A. C., Modesto A., Cunca R.,. Costa R. C, and Branco V., "REDE\#01: Reunião de Escolas de Design," Aveiro, Portugal, 2018.

[17] Costa N., Branco V., Costa R., Borges A., Cunca R., Modesto A., Silva A., "Mapping the research thread of PhDs in Design: a PhD citation analysis of the Portuguese doctorates," in 8th International Conference on Research into Design, 2021 (in press). 